\title{
Е.А. Бакланова
}

Новосибирский государственный технический университет

\section{Лексические особенности ранних рассказов В. Набокова на основе количественного анализа текстов}

Аннотащия: В статье изложены некоторые результаты исследования лексики ранних рассказов В. Набокова на основе использования метода количественного анализа текста. Представлено количественное и процентное соотношение частей речи в текстах, распределение слов по начальным буквам, отмечены особенности именования героев, частотные лексемы. На этой основе представлен имманентный анализ текстов.

The paper presents some results of the research on the vocabulary of the early short stories by V. Nabokov. The study is based on the quantitative text analysis. Account is given of the quantitative and percentage ratios of parts of speech in the texts as well as the distribution of words according to their initial letters. Peculiarities of naming the characters in the stories and frequent lexemes are noted. Based on the above results, an inherent text analysis of the texts is performed.

Ключевые слова: лексема, словоупотребление, повтор, соотношение частей речи, частота встречаемости, именование.

Lexeme, word usage, repetition, ratio of parts of speech, occurrence frequency, naming.

УДК: 81'42.

Контактная информащия: Новосибирск, пр. Карла Маркса, 20. НГТУ, кафедра русского языка. Тел. (383) 3153957. E-mail: russ@russ.fgo.nstu.ru.

Изучение лексических особенностей ранних рассказов В. Набокова на материале сборника «Возвращение Чорба» важно для определения приоритетов писателя: что он изображал (круг тем) и как он это делал (какую лексику использовал по преимуществу) в начале своего творческого пути. В статье представлены некоторые результаты применения метода количественного анализа текста. Обработка массива частотной лексики дала возможность выявить систему художественных концептов и, тем самым, приблизила к пониманию художественного мира писателя [Бакланова, 2006, с. 18-28].

В.В. Набоков придавал первостепенное значение форме, то есть, в числе прочего, словам. В его лекции о Л.Н. Толстом (Америка, Уэлсли, 40-е годы) читаем: «Слово, выражение, образ - вот истинное назначение литературы. Но не идеи» [Набоков, 1996, с. 248]. У набоковеда Б.М. Носика сказано, что Ходасевич, открывая Набоковские чтения (Париж, 1937 г.), определил главную тему писателя: «жизнь художника и жизнь приема в сознании художника». И далее приводятся слова Ходасевича об отношении Набокова к работе над формой, над словом: «...искусство не исчерпывается формой, но вне формы оно не имеет бытия и следственно смысла» [Носик, 2000, с. 323].

Использованный метод - именно количественный анализ, а не статистический, поскольку подсчитывались интересующие нас факты в каждом тексте и сравнивались их процентные соотношения. Например: подсчитывалось общее 
количество повторов в \% к общему числу лексем или количество имен существительных (прилагательных, глаголов) в \% к общему числу лексем. Таким образом, несущественным оказывалось то, что это не выборки в точном смысле этого слова, а целые тексты разной длины. «Авторские речевые стили, несомненно, во многом (если и не во всем) определяются устойчивыми для каждого автора соотношениями частот разных элементов языка. Теперь это не гипотеза, а утверждение, опирающееся на известные факты. Вспомним хотя бы те немногие статистические данные, которые получены из текстов Симонова и Шолохова» [Головин, 1971, c. 14].

Соотношение частей речи дало возможность сделать выводы об общем характере текстов. Распределение слов по начальным буквам в сборнике по сравнению со словами в русском языке представило собой определенный интерес. Рассмотрение имен собственных, нарицательных и местоимений в случае, когда автор не дал герою имя, показал предпочтения рассказчика и позволил расставить некоторые смысловые акценты. Таблица, построенная по принципу частотного словаря, дала богатейший материал для дальнейшего исследования.

Выбор в качестве материала для анализа раннего сборника рассказов В.В. Набокова объясняется следующими соображениями. Все пятнадцать текстов являются абсолютно разными по эстетической «тональности», по структуре. Например, «Порт» - лирическая бессюжетная зарисовка; «Сказка» - гротеск; «Письмо в Россию» - письмо, представляющее собой воспоминания и размышления; «Ужас» - исповедь; «Рождество» - аллюзия на факты собственной биографии; «Пассажир» - декларация художественного кредо рассказчика в форме диалога, напоминающего учебное упражнение; «Подлец» - парафраз на «Выстрел» А.П. Чехова. Таким образом, возможность исследовать разнохарактерные тексты, объединенные авторским языком, открывает перспективу для понимания специфики художественного мира автора.

Проанализировано 15 рассказов, из которых были выбраны все имена существительные (в том числе имена собственные), имена прилагательные и глаголы, поскольку именно они несут основную смысловую нагрузку. «И из этих слов перед нами складывается художественный мир произведения: из существительных - его предметный (и понятийный) состав; из прилагательных - его чувственная (и эмоциональная) окраска; из глаголов - действия и состояния, в нем происходящие» [Гаспаров, 2001, с. 18].

Правила выделения слов при подсчетах в целом аналогичны указанным в уже имеющейся работе [Частотный словарь рассказов А.П. Чехова, 1999, с. 910]. Основной единицей анализа является лексема: «лексемы, слово-типы, обладающие свойством “порождать” текстовые слова (слово-знаки)» [Частотный словарь русского языка, 1977, с. 11]. Подсчитывались слова, напечатанные отдельно. Супплетивные формы от разных основ и глаголы совершенного и несовершенного вида, а также существительные разного рода, образованные от одного корня (господин, госпожа), рассматривались как разные лексемы. Прилагательные представлены в полной форме в именительном падеже единственного числа мужского рода (ср.: райскими - райский). Глаголы представлены инфинитивами, в том числе в составных глагольных сказуемых (было будить - быть, будить). Но, в отличие от указанных словарей, нами не учитывались наречия, причастия и деепричастия, не различались омонимы. Имя считалось за одну единицу (Николай Степаныч, Картофельный Эльф) в случае, когда оно состояло из двух слов и в тексте употреблялось только в данной форме. Если в тексте имя и фамилия употреблялись отдельно, то слова тоже считались отдельно (Марк, Штандфусс). Местоимения учитывались лишь при подсчете имен в случае, когда автор не дал герою имя. Все лексемы приводятся в начальной форме, за исключением случаев, когда слово употребляется в контексте только в данной форме (например, глаза, губы использованы автором только во множественном числе). 
В сборнике было выделено 12060 лексем. Общее количество проанализированных словоупотреблений - 19700. По частям речи лексемы распределились следующим образом: имен существительных - 5190 (43\%), глаголов - 4160 (34,5\%), имен прилагательных - 2700 (22,3\%). Это позволяет предположить, что в начале творческого пути В. Набокову было важнее описать предметный мир, чем дать его характеристику. Сравнение с данными «Частотного словаря русского языка» показывает, что преобладание существительных над глаголами, а их над прилагательными характерно для художественной литературы $(23,44 \%, 18,96 \%$, $7,37 \%$ соответственно) [Частотный словарь русского языка, 1977, с. 927]. Разница в количестве процентов объясняется тем, что в «Частотном словаре» учитывались все грамматические формы глагола и другие части речи, а в данном исследовании - только три.

В таблице 1 отражены количественные данные: сколько словоупотреблений в каждом тексте (имен и глаголов), сколько лексем и как они распределяются по частям речи, сколько всего повторов (в том числе в \%), каково соотношение имен существительных, имен прилагательных и глаголов в \% к общему числу учитываемых лексем. Тексты во всех таблицах расположены в порядке убывания количества анализируемых словоупотреблений.

Таблица 1

Количественные данные: словоупотребления, лексемы, повторы, соотношения частей речи к общему числу лексем

\begin{tabular}{|c|c|c|c|c|c|c|c|c|c|c|c|}
\hline № & $\begin{array}{l}\text { Название } \\
\text { рассказа }\end{array}$ & 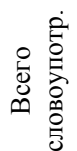 & $\begin{array}{l}\sum_{0} \\
0 \\
0 \\
0 \\
0 \\
0 \\
0 \\
0\end{array}$ & 良 & 它 & 㥕 & 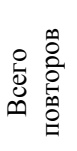 & $\%$ & \multicolumn{3}{|c|}{$\begin{array}{c}\text { Соотношение сущ., } \\
\text { прил., глаг. в \% к } \\
\text { общему числу } \\
\text { лексем }\end{array}$} \\
\hline & & & & & & & & & Сущ. & Прил. & Глаг. \\
\hline 1 & «Подлец» & 3639 & 1735 & 641 & 314 & 780 & 1904 & 52 & 37 & 18 & 45 \\
\hline 2 & $\begin{array}{l}\text { «Картофель- } \\
\text { ный Эльф» }\end{array}$ & 3053 & 1763 & 771 & 377 & 615 & 1290 & 42 & 43,7 & 21,4 & 34,9 \\
\hline 3 & «Сказка» & 1740 & 984 & 422 & 221 & 341 & 756 & 43 & 42,9 & 22,5 & 34,6 \\
\hline 4 & «Звонок» & 1408 & 880 & 374 & 162 & 344 & 528 & 37 & 42,5 & 18,4 & 39,1 \\
\hline 5 & «Бахман» & 1254 & 813 & 347 & 181 & 285 & 441 & 35 & 42,7 & 22,3 & 35 \\
\hline 6 & $\begin{array}{l}\text { «Возвращение } \\
\text { Чорба» }\end{array}$ & 1241 & 776 & 350 & 181 & 243 & 465 & 37 & 45,1 & 23,3 & 31,3 \\
\hline 7 & «Порт» & 1012 & 701 & 322 & 174 & 205 & 310 & 31 & 45,9 & 24,8 & 29,2 \\
\hline 8 & «Катастрофа» & 988 & 645 & 283 & 143 & 219 & 343 & 35 & 43,9 & 22,2 & 33,9 \\
\hline 9 & «Ужас» & 932 & 585 & 256 & 134 & 195 & 347 & 37 & 43,8 & 22,9 & 33,3 \\
\hline 10 & «Рождество» & 920 & 653 & 301 & 170 & 182 & 267 & 29 & 46 & 26 & 28 \\
\hline 11 & «Пассажир» & 845 & 563 & 222 & 138 & 203 & 282 & 33 & 39,5 & 24,5 & 36 \\
\hline 12 & «Благость» & 843 & 565 & 245 & 128 & 192 & 278 & 33 & 43,4 & 22,6 & 34 \\
\hline 13 & $\begin{array}{l}\text { «Путеводи- } \\
\text { тель по Бер- } \\
\text { лину» }\end{array}$ & 743 & 562 & 287 & 144 & 131 & 181 & 24 & 51 & 25,6 & 23,3 \\
\hline 14 & $\begin{array}{l}\text { «Письмо в } \\
\text { Россию» } \\
\end{array}$ & 573 & 444 & 210 & 131 & 103 & 129 & 22 & 47,3 & 29,5 & 23,2 \\
\hline 15 & «Гроза» & 513 & 395 & 160 & 113 & 122 & 118 & 23 & 40 & 29 & 31 \\
\hline
\end{tabular}


В целом наблюдается тенденция: чем больше текст, тем больше процент повтора лексем (от $52 \%$ в рассказе «Подлец» до $23 \%$ - в «Грозе»). Возможно, это сознательный прием. Чем больше пространство текста, тем интенсивнее автор направляет и регулирует познавательную деятельность читателя, то есть повторы у Набокова выполняют регулятивную функцию. Интересной представляется мысль Т.И. Сильман, связавшей повтор и подтекст: «Подтекст представляет собой в конечном счете тип рассредоточенного повтора, который возникает на фоне и с учетом непрестанного изменения и углубления контекстуальных связей, и именно в этом своем качестве несомненно доступен для языкового анализа» [Сильман, 1969, с. 89]. Здесь представлен имманентный анализ текстов, то есть выводы сделаны только на основе подсчетов слов - речь о подтексте не идет. Соотношение частей речи: почти во всех текстах преобладают имена существительные (чуть больше $40 \%$ ), затем идут глаголы (чуть больше $30 \%$ ), затем - имена прилагательные (чуть больше 20\%). Вероятно, писателю особенно важен был вещный мир (предметный состав художественного мира произведения по М.Л. Гаспарову).

Меньше всего процентное соотношение глаголов по отношению к другим анализируемым частям речи в рассказах: «Путеводитель по Берлину» $(23,3 \%)$ и «Письмо в Россию» (23,2\%). Это статические тексты, тексты-описания.

Самый динамичный рассказ - «Подлец», так как сюжет (супружеская измена и быстрая смена последовавших за этим событий) скоро движется к развязке, что передается преобладанием глаголов над другими частями речи (45\%). Автор задает быстрый темп чтения текста. Если упомянутые выше тексты-описания предполагают медленный темп чтения, то здесь - резкая перемена психологического состояния героя, его статуса и, следом, его действий, что передается отрывистой, иногда бессвязной речью: «Станция. Опять тронулись. Почему они его так мучат? Сегодня немыслимо умереть. Совершенно немыслимо. Что, если упасть в обморок? Нужно быть хорошим актером... Что предпринять? Что делать? Такое дивное утро...» [Набоков, 1990, т. 1, с. 357].

Следующий рассказ - «Звонок», где имен существительных немного больше, чем глаголов - $42,5 \%$ и $39,1 \%$ соответственно. Динамика этих двух текстов имеет различную природу. В первом - быстрая смена сильных чувств сопровождается внешним, событийным перемещением. Во втором тексте преобладает движение внутреннего плана - течение мыслей, чувств, воспоминаний, непосредственных ощущений: «Как она встретит его? Нежно? Или грустно? Или совсем спокойно? Она не баловала его в детстве. Ты не смеешь тут бегать, когда я играю на рояле» [Там же, с. 299].

Наименьшее количество имен прилагательных - в тех же текстах $(18 \%$ и $18,4 \%$ соответственно). Это тексты экзистенциального характера - переживания личностной (в первом случае) и личной (во втором) катастрофы. Причем в рассказе «Подлец» - глобальное нарушение отношений между членами литературной коммуникации: проникновение внутренней монологической речи героя в авторскую. (В синтаксисе - это несобственно-прямая речь.) Находясь в экзистенциальной ситуации, совершая перемещения (герой почти все время куда-то едет или идет), он думает, комментирует, оценивает (про себя). Его речь лаконична, порой бессвязна (для читателя, но ведь это внутренняя речь!) и не нуждается в «признаковости».

В рассказе «Звонок» почти нет нарушения отношений между членами литературной коммуникации. Автор дистанцирован от героя. Но сама ситуация - экзистенциальная ситуация встречи-невстречи героя с матерью - продиктовала автору такое соотношение исходного материала (слов): преобладание имен существительных $(42,5 \%)$, глаголов $(39,1 \%)$ на фоне относительно редкого использования имен прилагательных $(18,4 \%)$. Итак, для передачи сильных чувств автор использовал, по преимуществу, имена существительные. 
Они преобладают также в рассказе «Путеводитель по Берлину» - 51\%. Объяснение этому - в самом названии. Это рассказ - путеводитель, описывающий предметный мир - реалии берлинских улиц 30-х годов прошлого века. Текст разделен на 5 маленьких главок с названиями: «Трубы», «Трамвай», «Работы», «Эдем» и «Пивная», в каждой из которых описаны названные реалии. (В «Эдеме» рассказывается о посещении берлинского аквариума.) Жанр путеводителя подразумевает объективность. Здесь же рассказчик подчеркнуто субъективен, простодушен и подробно объясняет, чем именно прекрасны трубы, трамвай и все остальное: «Сегодня на снеговой полосе кто-то пальцем написал “Отто”, и я подумал, что такое имя, с двумя белыми “о” по бокам и четой тихих согласных посередке, удивительно хорошо подходит к этому снегу, лежащему тихим слоем, к этой трубе с ее двумя отверстиями и таинственной глубиной» [Набоков, 1990, т. 1, с. 336]. Трамвай прекрасен потому, что скоро исчезнет. Работы хороши, поскольку их можно видеть и слышать. Работают дорожные рабочие - рассказчик слушает удары молота: «Я слушаю их неторопливый звон, чугунные куранты, четыре повторяющиеся ноты» [Там же, с. 338]; «белый пекарь промахнул на ... велосипеде» - видит; «Дребезжит фургон» - слышит и т. д. Но самое интересное вывод: «Но, быть может, прекраснее всего - бланжевые, в розовых подтеках и извилинах, туши, наваленные на грузовик, и человек в переднике, в кожаном капюшоне с долгим затыльником, который берет тяжкую тушу на спину и, сгорбившись, несет ее через панель в румяную лавку мясника» [Там же, с. 338]. 3оопарк - это «земной рай, созданный человеком», а пивная замечательна тем, что она - «чье-то будущее воспоминание» [Там же, с. 340]. Два приведенных полностью отрывка (о трубе и о лавке мясника) типичны для текста в целом преобладанием имен над глаголами.

И еще три текста со значительным числом имен существительных: «Письмо в Россию» (47,3\%), «Рождество» $(46 \%)$ и «Порт» $(45,9 \%)$. Первый - фактически тоже путеводитель, но путеводитель по прошлому, поэтому для него справедливо все то, что сказано выше. Кроме того, автор заявляет о времени написания и, как следствие, об изменении восприятия окружающего: «Сейчас ночь. Ночью особенно чувствуешь неподвижность предметов, - лампы, мебели, портретов на столе» [Там же, с. 306]. Под знаком иного, не дневного, мира, написано письмо, состоящее из наблюдений, размышлений и замечаний. В тексте есть предложения, состоящие почти из одних имен: «Мода через века дышит: купол кринолина в середине прошлого века - это полный вздох моды, потом опять выдох, - сужающиеся юбки, тесные танцы» [Там же, с. 308].

«Порт» и «Рождество» - статичны, но причины этого разные. Первый напоминает картину южного порта и человека на ней, который созерцает, наблюдает, никуда особенно не спешит, он - «часть пейзажа». Герой на перепутье, в его жизни краткое затишье. Текст - фиксация того, что он видит, ощущает, вспоминает: «Человек в окне сказал:

- А я, Ляля, достал эти ноты. Помните?

Так и пахнуло, - почти нарочито, словно кто-то забавлялся тем, что выдумывает эту барышню, этот разговор, этот русский ресторанчик в чужеземном порту, - пахнуло нежностью русских захолустных будней...» [Там же, с. 293].

В рассказе «Рождество» - человек на пике горя. Жизнь остановилась, так как у него умер сын. Это экзистенциальная ситуация. Текст - фиксация этого состояния, воспоминаний, концентрация героя на вещах, которые «помнят» сына: «Он сел у голого письменного стола, строго, исподлобья, оглядел бледные в синеватых розах стены, узкий шкап вроде конторского, с выдвижными ящиками снизу доверху, диван и кресла в чехлах, - и вдруг, уронив голову на стол, страстно и шумно затрясся, прижимая то губы, то мокрую щеку к холодному пыльному дереву и цепляясь руками за крайние углы» [Там же, с. 322]. 
Таким образом, количественные подсчеты уже дают возможность делать приблизительные выводы о характере текстов, о зависимости количества повторов от величины текста, о зависимости статичности или динамичности текста от соотношения слов разных частей речи.

Были проведены подсчеты распределения словоупотреблений и лексем по начальным буквам. Аналогичная работа проводилась авторами «Частотного словаря русского языка» [Частотный словарь русского языка, 1977, с. 932-933]. Для нас представляла интерес сама возможность сравнить распределение слов по начальным буквам в русском языке и в сборнике текстов одного автора.

Наиболее часто в сборнике повторяются слова на букву $\mathbf{C}$ : в шести текстах из пятнадцати от 40\% до 59\% повторов. На букву П повторов меньше, в среднем около 20\%, за исключением двух текстов: «Подлец» и «Благость» (34\% и 38\% соответственно). В русском языке больше всего слов на букву П, а на С значительно меньше - сравнимо со словами на буквы Н, О, В. Согласно приведенным А.П. Журавлевым [1974] данным о символическом значении русских звуков самый частотный у Набокова звук $\mathbf{C}$ имеет следующие характеристики: плохой, отталкивающий, шероховатыцй, низменный, тускльй, тихий, короткий, трусливый, злой. Из положительно окрашенных характеристик: светльий, легкий. Фонетическое значение опосредованно, но все же связано с эмоциональным строем текста. По нашему мнению, из приведенных характеристик существенными оказались две последние, поскольку общий эмоциональный тон сборника светлый и легкий. Что касается цветовых соответствий, то А.П. Журавлев отмечает: «четкие звуко-цветовые соответствия ... прослеживаются в основном для гласных» [Журавлев, 1974, с. 51]. Писатель же видел все звуки всех знакомых ему языков в цвете. Например, русский звук $\mathbf{C}$ для Набокова был влажно-голубого цвета. (Об этом см. в автобиографии «Другие берега» [Набоков, 1990, т. 4, с. 146-147]. Для главного героя романа «Дар» Федора Годунова-Чердынцева $\mathbf{C}$ становится сияющим: «и вы бы оценили мое сияющее “с", если я мог бы вам насыпать в горсть тех светлых сапфиров, которые я ребенком трогал... когда моя мать... переливала свои совершенно небесные драгоценности из бездны в ладонь, из шкатулок на бархат...» [Набоков, т. 3, 1990, с. 68]. Подробно о хроместезии, присущей В. Набокову, рассказано в книге Д.Б. Джонсона [Джонсон, 2011, с. 21-47].

Интересен подход В. Набокова к образу повествователя и к именованию своих героев. От первого лица повествование ведется в пяти рассказах, в остальных от третьего лица. В трех текстах внутренний адресат (женщина) не назван по имени - используется местоимение второго лица. В случае повествования от третьего лица имя любимой женщины может быть названо (см. «Бахман», «Подлец», «Катастрофа») или нет. В последнем случае вместо имени собственного или местоимения использована перифраза: «...та, которую он никогда не называл по имени...» [Набоков, 1990, т. 1, с. 285]. Разумеется, автор использовал прием табуирования сознательно.

Иногда для именования героев В. Набоков использует их социальный статус: писатель, критик («Пассажир»); семейное положение: сын («Рождество»), дочь («Возвращение Чорба»); статус по отношению к рассказчику: друг («Письмо в Россию»), приятель («Путеводитель по Берлину»); пол и возраст: старик («Гроза»), старушка («Благость»), женщина («Возвращение Чорба»). Жанр короткого рассказа вообще не предполагает подробную характеристику героев, но здесь подчеркивается полное отсутствие каких-то индивидуальных черт. Названный так герой - схематичен, он формальный участник литературной коммуникации. Например: «Я проснулся и увидел ногу.

- Виноват? - переспросил скромный критик, подавшись вперед и подняв указательный палец.

- Я увидел ногу, - повторил писатель» [Там же, с. 364]. 
Редко герой имеет имя и фамилию: Фред Добсон («Картофельный Эльф»), Марк Штандфусс («Катастрофа»), обычно только фамилию: Никитин («Порт»), Слепцов («Рождество») или только имя: Антон Петрович («Подлец»), Николай Степаныч («Звонок»). В случае, когда автор наделял персонажа именем, он в начале текста представлял и характеризовал его. Например: «А на самом деле имя его было Фредерик Добсон. Приятелю своему, фокуснику, он рассказывал о себе так: «Кто в Бристоле не знал детского портного Добсона? Я - сын его» [Набоков, 1990, т. 1, с. 378-379]. Интересно, что это абсолютное начало текста, а кроме того, автор предоставляет самому герою возможность рассказать о себе. Еще пример: «Сквозь темный блеск шел он домой, - Марк Штандфусс, приказчик, полубог, светловолосый Марк, счастливец в высоком крахмальном воротнике» [Там же, c. 368]. Сразу обращает на себя внимание парадоксальная характеристика персонажа.

Фамилия может быть достаточно экзотической, напоминающей прозвище: Бахман («Бахман»), Чорб («Возвращение Чорба»). Впрочем, и первое, и второе имя поддаются дешифровке. Например, в имени музыканта Бахмана содержится другое, известное - Бах. Кроме того, Бахман созвучно имени Пахман - это реальный пианист, известный в Европе в тридцатых годах XX века. Герой рассказа «Подлец» - Берг, имеет только фамилию, зато похожий герой уже был у Л.Н.Толстого в «Войне и мире». В дальнейшем В. Набоков достигнет удивительного мастерства в неназывании действующих лиц своих произведений, например в «Защите Лужина» героиня не имеет имени, а сам Лужин получает имя и отчество только в последней фразе романа.

Таблица 2 построена по принципу частотного словаря. В ней представлено 180 наиболее частотных лексем, встречающихся более трех раз в двух и более текстах. Например, лексема черный присутствует в 10 текстах 91 раз без учета возможных единичных повторов в остальных текстах. Ниже представлен фрагмент таблицы.

Частота встречаемости лексем в текстах

\begin{tabular}{|l|l|l|l|}
\hline$№$ & Лексемы & Колич. рассказ. & Всего повт. \\
\hline 1 & быть & 15 & 410 \\
\hline 2 & стать & 15 & 95 \\
\hline 3 & рука & 13 & 108 \\
\hline 4 & глаза & 12 & 96 \\
\hline 5 & лицо & 12 & 94 \\
\hline 6 & голова & 10 & 51 \\
\hline 7 & дом & 10 & 52 \\
\hline 8 & окно & 10 & 59 \\
\hline 9 & улица & 10 & 65 \\
\hline 10 & черный & 10 & 91 \\
\hline 11 & выйти & 9 & 45 \\
\hline 12 & говорить & 9 & 44 \\
\hline 13 & дверь & 9 & 71 \\
\hline 14 & знать & 9 & 67 \\
\hline 15 & мочь & 9 & 62 \\
\hline 16 & стоять & 9 & 37 \\
\hline 17 & человек & 9 & 55 \\
\hline 18 & большой & 8 & 33 \\
\hline 19 & сказать & 8 & 158 \\
\hline 20 & сидеть & 8 & 40 \\
\hline 21 & белый & 7 & 39 \\
\hline 22 & волосы & 7 & 34 \\
\hline 23 & видеть & 7 & 37 \\
\hline 24 & думать & 7 & 28 \\
\hline 25 & комната & 7 & 47 \\
\hline 26 & нога & 7 & 56 \\
\hline 27 & ночь & 7 & 40 \\
\hline 28 & пальцы & 7 & 34 \\
\hline 29 & плечо & 7 & 30 \\
\hline 30 & стол & 7 & 48 \\
\hline & & & \\
\hline
\end{tabular}


Верхнюю строчку в таблице занимает бытийный глагол быть, повторяющийся во всех 15 текстах 410 раз. Минимальное число повторов, отраженных в таблице, - 6 (для некоторых лексем, употребленных автором не меньше, чем в двух текстах). Таким образом, в таблицу не включены некоторые частотные лексемы, встретившиеся только в одном тексте. Основанием для такого отбора послужило следующее соображение: повторы в масштабе одного текста важны для анализа преимущественно этого текста. Лексемы, встречающиеся чаще, чем в одном тексте, несут более значимую смысловую нагрузку: кроме актуального смысла в данном контексте они выполняют регулятивную функцию, а также служат показателями своеобразия словаря писателя.

Среди слов, представленных в таблице, больше всего существительных 105 , глаголов - 46, прилагательных - 29. Это, в целом, соответствует общему соотношению частей речи в сборнике (см. табл. 1), но в процентном соотношении видна разница: среди частотных лексем (см. табл. 2) существительных - 58,3\%, глаголов - 25,5\%, прилагательных - 16,1\%. Среди всех проанализированных лексем (см. табл. 1) существительных - 43\%, глаголов - 34,5\%, прилагательных $22,3 \%$. Абсолютное преобладание имен существительных среди частотных лексем объясняется семантической спецификой этой части речи - обозначать субъект или объект. В мире текстовой реальности - свой субъектный и вещный мир, выстроенный чрезвычайно тщательно, несмотря на малый объем самих текстов. Понятийная специфика имен существительных позволяет рассматривать их как весьма существенные для понимания особенностей художественного мира писателя.

Для исследования лексики, использованной в рассказах В.В. Набоковым, достаточно эффективным стал прием количественного анализа. На основе данных, представленных в таблице 2, были созданы текстовые лексико-тематические группы. По составу этих групп, по соотношению в них более частотных и менее частотных лексем, по корреляциям, связывающим лексемы, были сделаны выводы, приблизившие нас к пониманию художественной картины мира автора [Бакланова, 2006, с. 15-18]. Художественный мир писателя или поэтическая картина мира - это выраженная в текстах концептуальная картина мира, опосредованная языком. По мнению Н.С. Болотновой, «поэтическую картину мира автора можно интерпретировать... как эстетическое отражение в текстовой деятельности концептосферы автора, как систему художественных концептов, вербализованных в тексте и творчестве писателя в целом» [Болотнова, 2003, с. 205].

\section{Литература}

Бакланова Е.А. Слово и имплицитный смысл в ранних рассказах В.В. Набокова (на материале сборника «Возвращение Чорба»): Автореф. дис. ... канд. филол. наук. Томск, 2006.

Болотнова Н.С. Поэтическая картина мира и ее изучение в коммуникативной стилистике текста // Сибирский филологический журнал. 2003. № 3/4. С. 198-207.

Гаспаров М.Л. О русской поэзии: Анализы, интерпретации, характеристики. СПб., 2001.

Головин Б.Н. Язык и статистика. М., 1971.

Джонсон Д.Б. Миры и антимиры Владимира Набокова. СПб., 2011.

Журавлев А.П. Фонетическое значение. Л., 1974.

Набоков В.В. Собр. соч.: В 4 т. М., 1990.

Набоков В.В. Лекции по русской литературе. М., 1996.

Носик Б.М. Мир и Дар Набокова. СПб., 2000.

Сильман Т.И. Подтекст как лингвистическое явление // Филологические науки. 1969. № 1. С. 84-91.

Частотный словарь рассказов А.П. Чехова. СПб., 1999.

Частотный словарь русского языка / Под ред. Л.И. Засориной. М., 1977. 